\title{
The Natural History of Untreated Sarcomatoid Renal Cell Carcinoma: An Autopsy Report
}

\author{
Tatsuo Nakagawa \\ Department of Urology, Nagano Matsushiro General Hospital, Nagano, Japan
}

\section{Key Words}

Carcinoma, natural history $\cdot$ Sarcomatoid renal cell

carcinoma

\begin{abstract}
Objective: To report a case of an autopsy that disclosed an untreated sarcomatoid renal cell carcinoma (RCC) with a 9-year natural history. Clinical Presentation and Intervention: An 86-year-old woman presented with acute cystitis. Ultrasonography revealed an incidental left renal mass measuring $2 \times 3 \mathrm{~cm}$. After 8.9 years, multiple liver metastases were detected on ultrasound. After 9.0 years, the tumor had increased by $3.5 \mathrm{~cm}$ from the initial size, and multiple lung metastases were also detected. After 9.1 years, the patient developed multiple metastases and died from progressive disease at the age of 95 . On autopsy, metastases were found in both lungs, bilateral hilar lymph nodes of the lung, the liver, both adrenal glands and the bone marrow. Conclusion: This case showed a probable slow transition from typical RCC to sarcomatous elements that remained untreated for 9 years before the patient died.
\end{abstract}

Copyright $\odot 2009$ S. Karger AG, Basel

\section{Introduction}

The natural history of renal tumors is not well known since most are surgically treated at the time of diagnosis. We report a case of an untreated sarcomatoid renal cell carcinoma (RCC) with a 9-year natural history that was discovered upon autopsy.

\section{Case Report}

An 86-year-old woman presented with acute cystitis at our office in July 1997. The patient was symptom-free after treatment for cystitis, but ultrasonography disclosed an incidental left renal mass measuring $2 \times 3 \mathrm{~cm}$. In August 1997, an abdominal computed tomography (CT) scan was compatible with a left RCC (fig. 1). No metastasis was found (M0). Surgical intervention was offered to the patient, but she and her family refused an operation because she was aged and had comorbidities of Alzheimer's and coronary artery disease. Renal ultrasonography performed 16 months later showed that the tumor was unchanged in size, but after 19 months, it had increased $1 \mathrm{~cm}$ on ultrasound. Because the patient did not have any symptoms, she refused further investigations. Then, 8.2 years after presentation, the patient presented with gross hematuria that continued without increasing anemia. Blood transfusions were not administered thereafter. The size of the mass had increased $2.3 \mathrm{~cm}$ on CT, but no lung or liver metastases were found. After 8.9 years, multiple liver metastases were detected on ultrasound. The last CT scan was done after 9.0 years, and the tumor had increased by $3.5 \mathrm{~cm}$ from the initial CT. Multiple lung metastases were also detected. Overall, the growth rate was $0.35 \mathrm{~cm} /$ year by CT. After 9.1 years, the patient developed

\section{KARGER}

Fax +4161306 1234 E-Mail karger@karger.ch www.karger.com (c) 2009 S. Karger AG, Basel

$1011-7571 / 09 / 0186-0490 \$ 26.00 / 0$

Accessible online at:

www.karger.com/mpp
Tatsuo Nakagawa, MD, $\mathrm{PhD}$

Nagano Matsushiro General Hospital

183 Matsushiro, Matsushiro-machi, Nagano-shi

Nagano 381-1231 (Japan)

Tel. +81 26278 2031, Fax +81 26278 9167, E-Mail tatsuo-n@mxl.avis.ne.jp 

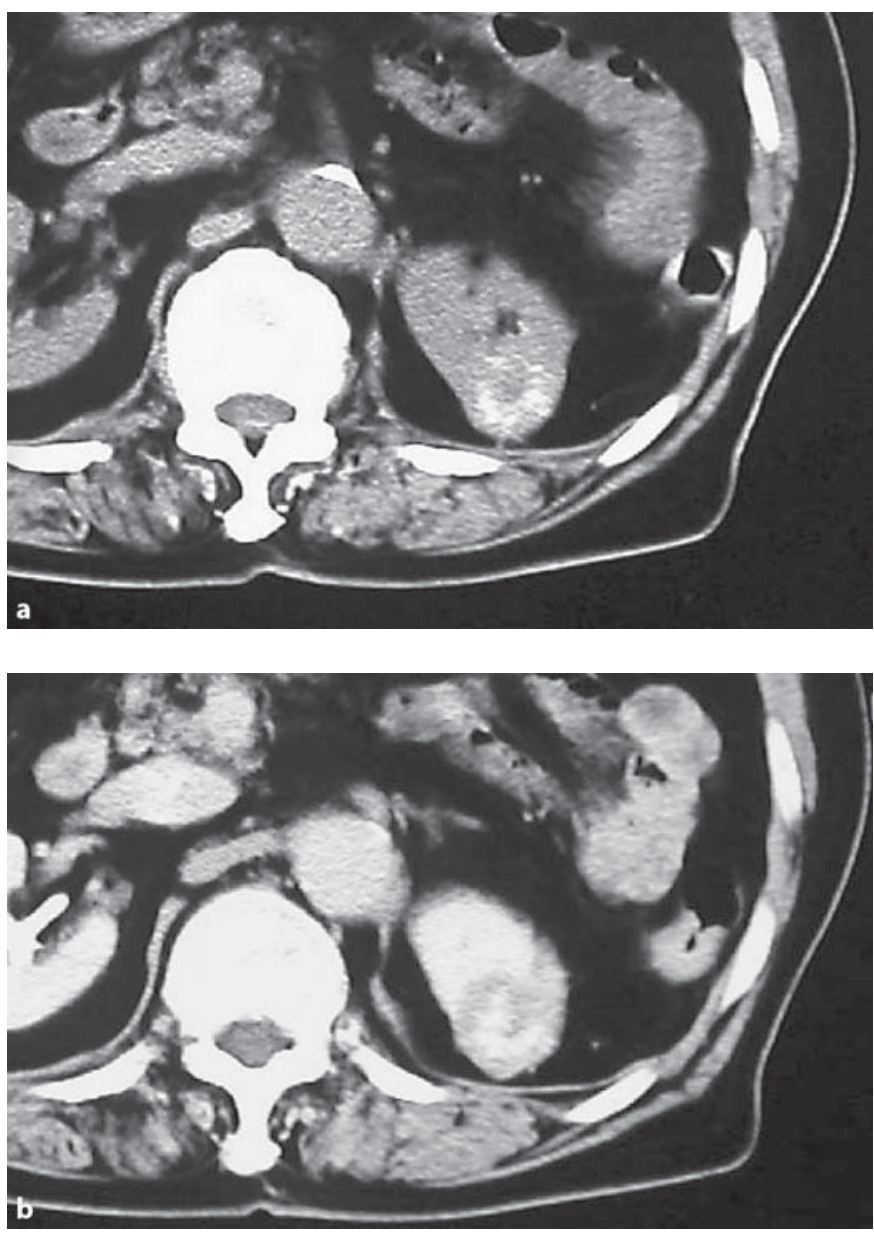

Fig. 1. a Plain CT showing calcification in the left kidney. b Contrast-enhanced CT showing a $2.7-\mathrm{cm}$ mass in the left kidney.

multiple metastases and died from progressive disease at the age of 95.

On autopsy, histological examination of the left kidney confirmed RCC. An $11 \times 5 \times 5 \mathrm{~cm}$ mass with marked central necrosis replaced the upper and the middle pole of the left kidney. Microscopically, the renal mass showed a grade 3 RCC consisting of both spindle cells and clear cells (fig. 2). The percentages were $90 \%$ for spindle cells and $10 \%$ for clear cells. The histopathological diagnosis was a sarcomatoid RCC. Metastases were found in both lungs, bilateral hilar lymph nodes of the lung, the liver, both adrenal glands and the bone marrow.

\section{Discussion}

Active surveillance of small, incidentally detected renal masses is increasingly viewed as a valid option in carefully selected patients. The prognosis of sarcomatoid

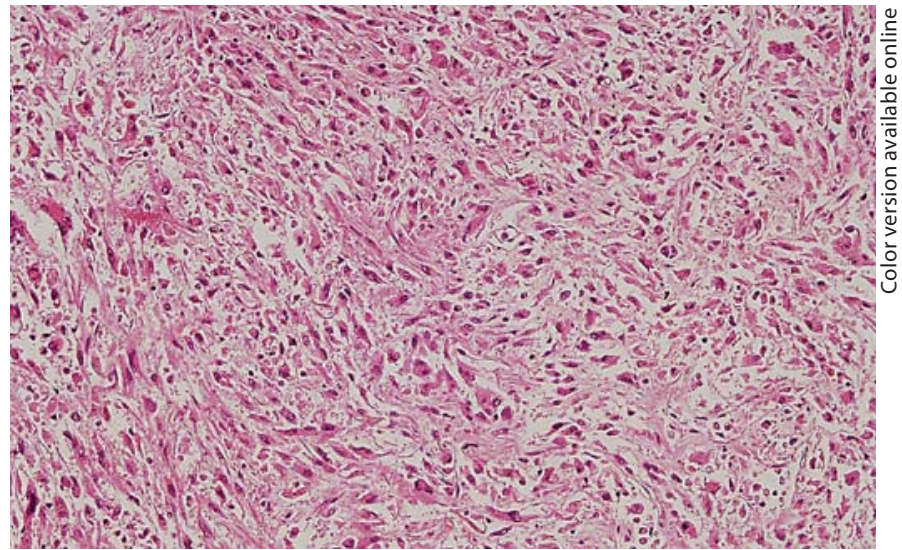

Fig. 2. Histological image of the tumor. Spindle-shaped tumor cells were detected. Hematoxylin-eosin. $\times 125$.

RCC is usually very poor. However, in this case, the small sarcomatoid RCC did not grow rapidly. At present, ablative therapy of small renal tumors might be acceptable for the elderly with limited life expectancy or/and patients with comorbidities. However, more prospective trials are needed to define the role of ablative treatment for these patients in the management of early-stage sarcomatoid RCC. For an 86-year-old Japanese woman in 1997, a 10 year life expectancy was $27 \%$ in a cohort from the Japanese National Cancer Center [1].

Sarcomatoid RCC, first reported by Farrow et al. [2], is a tumor of mixed form comprised of a differentiated cancer element and a spindle cell element showing solid sarcomatoid proliferation. Histopathogenesis of sarcomatoid RCC is believed to arise from the clear cell or chromophilic type [3]. Sarcomatoid carcinoma accounts for $1-6.5 \%$ of all renal cell carcinomas and is the type with the worst prognosis [4]. The median survival time after diagnosis is in the range of 6 months with a 3-year survival rate of only $19 \%$ [3]. In our case, the sarcomatoid RCC was discovered incidentally and remained asymptomatic for more than 8 years. Although the reason for this relatively long-term survival is not clear, it may be secondary to the slow transition from typical RCC to sarcomatous elements.

In the largest combined series to date, Chawla et al. [5] reported a meta-analysis of the available data on active surveillance. Nine single institutional series met the authors' inclusion criteria, accounting for 234 renal lesions undergoing a period of active surveillance. The overall mean lesion size was $2.60 \mathrm{~cm}$. The overall mean duration of follow-up was 34 months. Observed mean growth rates 
in individual series were $0.09-0.86 \mathrm{~cm} /$ year, with an overall combined mean of $0.28 \mathrm{~cm} /$ year.

In the present case, initial tumor size, duration of follow-up and tumor growth rate were $2.7 \mathrm{~cm}, 109$ months and $0.35 \mathrm{~cm} /$ year, respectively. High-grade and/or sarcomatoid RCCs may grow rapidly and metastasize early. In our case, the average growth rate was not high compared with other reports. We noted, however, that whereas the initial growth was slow, the later growth accelerated in our case.

There are a number of treatment options for localized RCC. In 1997, arterial embolization of the tumor as a palliative approach could have been beneficial in this patient. Cytokines and immunotherapy have limited efficacy, but possibly might have kept the patient alive longer. Currently, similar patients not suitable for open or laparoscopic surgery due to poor performance status with smaller peripheral tumors should be considered for thermal ablative techniques. At present, percutaneous or laparoscopic cryoablation and radiofrequency ablation have been suggested as alternatives to surgical treatment [6].

\section{Conclusion}

This case showed a probable slow transition from typical RCC to sarcomatous elements that remained untreated for 9 years before the patient died.

\section{Acknowledgments}

The author wishes to express his sincere appreciation for the assistance provided by Dr. Allan Toguri at the Scarborough Hospital in Toronto, Canada.

\section{References}

1 Cohort life tables based on annual life tables for the Japanese nationals covering the years 1962-2006. http://ganjoho.ncc.go.jp/professional/statistics/cohort01.html.

2 Farrow GM, Harrison EG, Utz DC: Sarcoma and sarcomatoid and mixed malignant tumors of the kidney in adults. Part III. Cancer $1968 ; 22: 556-563$
Ro JY, Ayala AG, Sella A, Samuels ML, Swanson DA: Sarcomatoid renal cell carcinoma: clinicopathologic. A study of 42 cases. Cancer 1987;59:516-526.

4 Japanese Urological Association and Japanese Pathological Society (eds): General Rule for Clinical and Pathological Studies on Renal Cell Carcinoma, ed 3, rev. Tokyo, Kanehara Shuppan, 1999.
5 Chawla SN, Crispen PL, Hanlon AL, Greenberg RE, Chen DY, Uzzo RG: The natural history of observed enhancing renal masses: meta-analysis and review of the world literature. J Urol 2006;175:425-431.

6 Marberger M, Mauermann J: Ablative therapy of renal tumors; in Wein AJ (ed): Campbell-Walsh Urology, ed 9. Philadelphia, Saunders, Elsevier, 2007, vol 2, pp 18101818. 